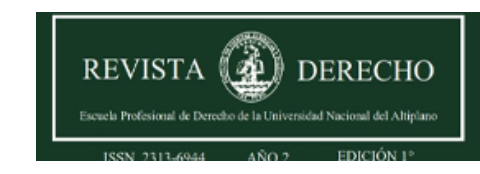

Revista de Derecho

ISSN: 2313-6944

ISSN: 2707-9651

revistaderecho@unap.edu.pe

Universidad Nacional del Altiplano

Perú

\title{
ADMISIBILIDAD DE LA PRUEBA PERICIAL EN SUDAMÉRICA
}

Tito Chura, Naruska

ADMISIBILIDAD DE LA PRUEBA PERICIAL EN SUDAMÉRICA

Revista de Derecho, vol. 5, núm. 2, 2020

Universidad Nacional del Altiplano, Perú

Disponible en: https://www.redalyc.org/articulo.oa?id=671870937012

DOl: https://doi.org/10.47712/rd.2020.v5i2.86

\section{(c) (1)}

Esta obra está bajo una Licencia Creative Commons Atribución 4.0 Internacional. 


\section{ADMISIBILIDAD DE LA PRUEBA PERICIAL EN SUDAMÉRICA}

Admissibility of expert evidence in south america

Naruska Tito Chura

Ministerio Publico, Perú

naruskat@gmail.com
DOI: https://doi.org/10.47712/rd.2020.v5i2.86

Redalyc: https://www.redalyc.org/articulo.oa?

$\mathrm{id}=671870937012$

Recepción: 30 Septiembre 2020

Aprobación: 25 Octubre 2020

Publicación: 27 Octubre 2020

\section{ReSUMEN:}

El derecho comparado es una alternativa para adoptar un punto de vista general y completo sobre la admisibilidad de la prueba pericial en Perú, Colombia y Chile. Con la finalidad conocer sobre los diferentes enfoques que se dan en los procesos de admisibilidad en Sudamérica, para ello se realizará una búsqueda bibliográfica y utilización de descriptores.

La admisibilidad de la prueba pericial, tiene un manejo diferente a pesar de temer un mismo modelo procesal penal, es necesario elevar las exigencias de admisibilidad de la prueba pericial, el incursionamiento progresivo de valoración en cuanto a la cientificidad de la prueba, la necesidad de la opinión experta, idoneidad del perito y confiabilidad de la pericia.

Palabras Clave: Admisibilidad, Prueba pericial, Sudamérica.

\section{Abstract:}

Comparative law is an alternative to adopt a general and complete point of view on the admissibility of the expert evidence in Perú, Colombia and Chile. In order to learn about the different approaches that occur in the admissibility processes in South America, for this a bibliographic search and use of descriptors will be carried out. The admissibility of the expert evidence has a different handling despite fearing the same criminal procedural model, it is necessary to raise the admissibility requirements of the expert evidence, the progressive incursion of assessment in terms of the scientificity of the evidence, the need to the expert opinión, suitability of the expert and reliability of the expertise.

KEYWORDS: Admissibility, Expert evidence, South America.

\section{INTRODUCCIÓN}

La cualidad de admisibilidad de una prueba es el resultado de la labor intelectual desarrollada por el juez, valoración racional y ponderada de los factores de pertinencia y autenticidad que intrínsecamente deben contener las solicitudes probatorias. Los criterios que una pericia científica para su validez en juicio debía ser aceptada por la comunidad científica.

En la actualidad no se conoce con precisión sobre los procesos de admisibilidad en países de Sudamérica que tienen un mismo sistema proceso penal, para el cual es derecho comparado es una herramienta útil para su descripción. Se realizar una búsqueda bibliográfica, lo que servirá para alcanzar el objetivo plantado de analizar sobre los procesos de admisibilidad en Sudamérica.

\section{MATERIAL Y MÉTODOS}

Para la localización de los documentos bibliográficos se utilizaron varias fuentes documentales, descriptores científicos, mapas conceptuales, lectura crítica, buscadores bibliográficos como google académico, Academia. Edu, Redalyc, Base. 


\section{1.- ADMISIBILIDAD DE LA PRUEBA PERICIAL EN EL PERÚ}

Uno de los aspectos frecuentes en juicio oral es la relación a la admisibilidad de la prueba de oficio no regulada en el código de Procedimientos penales, aunque si contenida en el código procesal penal del 2004 (Art. 385). La admisión de los medios de prueba es una etapa del procedimiento probatorio que se encuentra bajo la exclusiva competencia del Juez, siendo aquel quien determine si se admite o no el medico de prueba, condicionada al cumplimiento de los plazos legales para su proposición, la satisfacción de las cargas específicas, su legalidad y pertinencia (Reyna 2000). función sagrada del juez de administrar justicia (Azarcón 1997). El rol del juez dentro del proceso debe ser activo y dinámico, siempre dentro del marco que le faculta la ley; en ese sentido, la facultad judicial de actuar prueba de oficio, se convierte en un instrumento procesal que contribuye a lograr la finalidad del proceso: alcanzar la verdad (Córdova Pardo 2019), utilice los medios de prueba pertinentes, más no un medio de prueba que ha vulnerado alguna norma del ordenamiento jurídico (Ortiz 2018). La prueba que pretenda ser incluida en el proceso ha de reunir necesariamente dichos requisitos, pues su incumplimiento será motivo de inadmisión de la misma. Respecto a la utilidad de la prueba, el apartado segundo del art. 283 LEC señala que aquellas evidencias que no contribuyan a aclarar la situación polémica serán inútiles. (Osco Escobedo 2019).

El medio de prueba es ofrecido en la etapa intermedia debe estar contenido de relevancia para que pase el filtro de admisibilidad; etapa en la que el juez tiene en cuanta innegables criterios de admisibilidad: relevancia, pertinencia, utilidad, necesidad (Ferrer 2008). He ahí la importancia del tamiz de admisibilidad que debe ser sometido el dato o información que se pretende que llegue a juicio, la prueba descansa en un criterio lógico, como es la relevancia de la prueba (Lluch 2013).

El tribunal constitucional señala que, una de las garantías que asiste las partes a las partes del proceso es la de presentar los medios probatorios necesarios que posibiliten crear convicción en el juzgador sobre la veracidad de los argumentos, el derecho a la prueba también está sujeta a restricciones o limitaciones derivadas tanto de la necesidad de que sean armonizados con otros derechos o bienes constitucionales; limites extrínsecos, como la propia naturales del derecho en cuestión y limites intrínsecos (Cas, N²81 - 2011- Moquegua, F.J. 3.3.) (Varga 2018). Entre los criterios de admisibilidad intrínsecos de admisibilidad de la prueba tenemos el de pertenencia, utilidad o relevancia, necesidad, entre los criterios extrínsecos son de carácter genérico (restricciones de orden legal que afectan cualquier medio probatorio) y especifico (limitaciones que inciden sobre el tipo de prueba en particular) (Ore 2018).

El juicio de pertinencia de las pericias; para su admisibilidad esta debe efectuarse en base de parámetros objetivos que son tres; 1) que los extremos del parámetro pericial sean de carácter técnico (carácter técnico); 2) que los extremos del dictamen guarden relación con los hechos controvertidos (pertinencia); 3) que los extremos del dictamen no hayan sido admitidos por las partes (ausencia de conformidad) lo que constituyen criterios generales de admisión de la prueba. Entre los criterios especiales de admisibilidad de la prueba pericial tenemos; necesidad del conocimiento experto; Idoneidad del perito, confiabilidad del peritaje (Varga 2018).

\section{2.- ADMISIBILIDAD DE LA PRUEBA PERICIAL EN COLOMBIA}

Los procesos penales colombianos consagran diferentes estándares de valoración en la admisibilidad de la prueba a cargo de los jueces. Los jueces aplican reglas de la experiencia, la ciencia y la lógica, identificándose cuál es el conocimiento real que los mismos tienen en torno al alcance de la valoración racional de la prueba y el grado de conocimiento que exigen tanto en el proceso civil y penal para dictar sentencia (Bustamante 2010). En el sistema penal la admisibilidad de los elementos probatorios se encuentra a cargo del juez que luego de una adecuada valoración se forja el respectivo juicio de admisibilidad bajo los parámetros establecidos para tal fin por la legislación y la jurisprudencia colombiana, y que finalmente se convierten en pruebas dentro del ciclo de la audiencia del juicio oral (Iriarte 2005), se cuenta para ello las normas procesales penales 
existentes en la ley 906 de 2004, como son los artículos 344 inciso final, 357 inciso final de dicha ley procesal, en concordancia con los principios de pertinencia y admisibilidad, establecidos en los artículos 375 y 376 del citado estatuto y, además apoyándose en la jurisprudencia nacional (Lizcano and Barbosa 2011). Corte Constitucional Colombiana ha reconocido que el sistema procesal colombiano ha tomado fuente en la jurisprudencia norteamericana (Jiménez Ramírez 2014).

El juicio admisibilidad por parte del juez de conocimiento debe efectuarse a través de una valoración, basada en las reglas de la sana critica, verbi gracia, reglas de la lógica, de la ciencia, experiencia; unido a la guía para su discernimiento, su raciocinio, el análisis crítico; es decir, el juez de conocimiento para ese juicio de admisibilidad, debe apoyarse en la ciencia y la tecnología con el uso de su discrecionalidad por la fundamentación legal y jurisprudencial que se tiene para ese momento procesal y el deseo inquebrantable de preservar la seguridad jurídica. Admisión depende del previo análisis de pertinencia y relevancia (artículos 375 y 376 del C.P.P), Vale decir, que el juicio de admisibilidad que debe realizar el juez de conocimiento y que comprende los aspectos de pertinencia1 12, legalidad, autenticidad, ser valorados por el juez de conocimiento, a través del juicio de admisibilidad contemplados en los artículos 375 y 376 del C.P.P., en donde el funcionario da un valor significativo, equivalente a la relevancia del medio de conocimiento, en defensa de las garantías procesales y el debido proceso de las partes e intervinientes.

También el artículo 376 de la ley 906 de 2004, establece: Admisibilidad. "Toda prueba pertinente es admisible, salvo:

a) Que exista peligro de causar grave perjuicio indebido.

b) Probabilidad de que genere confusión en lugar de mayor claridad al asunto, o exhiba escaso valor probatorio.

c) Que sea injustamente dilatoria del procedimiento 186(Lizcano and Barbosa 2011).

Se toma en cuenta también los siguiente principios; Principio de prevalencia constitucional, principio de interés público o general del proceso, principio de obligatoriedad de los principios fijados en la ley, principio de imparcialidad del juez, principio de autonomía e independencia del juez, principio de la supresión de la permanencia de la prueba, principio de presunción de inocencia (status inocentae), principio de in dubio pro reo, principio de la carga de la prueba por el estado (onus probando incumbit accusationis), principio del derecho a guardar silencio y a no auto incriminarse, principio del respeto a la dignidad humana (humanae dignitas), principio de legalidad, principio de libertad probatoria, principio de contradicción, principio de la necesidad de la solicitud probatoria, principio de la publicidad de la solicitud probatoria, principio de la pertinencia y relevancia de la solicitud probatoria, principio de la unidad y comunidad de la prueba, principio de la conducencia o idoneidad de la prueba y

principio de la autenticidad de la prueba (Estrada Vélez 2016).

\section{3.- ADMISIBILIDAD DE LA PRUEBA PERICIAL EN CHILE}

La Constitución Política de la República de Chile, no utiliza la expresión debido proceso, por un explícito deseo de no reconocer esta garantía a las personas, si no para no emplear una denominación que tiene sus orígenes en el derecho anglosajón (due process of law). El constituyente 1980 optó por usar la expresión equivalente de "racional o justo procedimiento" (artículo 19, núm. 3, inciso5, CPR) (Bordalí and Iván 2013), al igual que el proceso de admisibilidad de la prueba.

Los jueces de garantía operan en la lógica que, de acuerdo con lo establecido en el artículo 276 inciso cuarto del CPP, la regla general del sistema es que toda prueba presentada debe ser admitida si no concurre una causal de exclusión, lo que justifica que no haya necesidad de elaborar un fundamento adicional (Aguilar 2014).

Lamentablemente, las razones que los jueces consideran para la admisibilidad de esta prueba no son registradas en las resoluciones judiciales en que ello ocurre, no desarrollan las razones por las que se admite la evidencia, lo que es una cuestión común en el funcionamiento del sistema tratándose de todo tipo de prueba. 
Tampoco existe doctrina en la materia que me permita hacer este trabajo de identificar los argumentos a favor de la admisibilidad (Ramos 2013), Pero si hay la necesidad de conocimiento experto como requisito central para la admisibilidad de la prueba pericial (Duce Julio 2016).

La doctrina chilena añade e impone tres exigencias adicionales para admitir a juicio la prueba pericial: la necesidad del conocimiento experto, la idoneidad del experto y la confiabilidad de la información experta. El CPC en su Art, 413.2, se encuentra un requisito de admisibilidad en cuanto a la idoneidad del experto que señala que no pueden ser peritos, "los que no tengan título profesional expedido por la autoridad competente, como se puede apreciar, se trata de una regla redactada en clave de admisibilidad de la prueba y no valoración de la misma. Es decir si la persona no reúne las condiciones explicitadas en la norma se trata de una prueba que en principio no podrá utilizarse. En el Art. 289 se establece que las partes podrán recabar informes elaborados por peritos de su confianza y solicitar sean citados a declarar en la audiencia de juicio, acompañado los comprobantes que acrediten la idoneidad profesional del perito. Es decir, el juez admitirá la prueba pericial cuando considere que los peritos otorgan suficientes garantías de seriedad u profesionalismo (Varga 2018).

Así, el artículo 314 señala explícitamente que El Ministerio Público y los demás intervinientes podrán presentar los informes elaborados por los peritos de su confianza y solicitar en la audiencia de preparación de juicio oral que éstos fueren citados a declarar a dicho juicio. El artículo 316, por su parte, señala que El juez de garantía admitirá los informes y citará a los peritos cuando... En consecuencia, estas normas indican claramente que el informe pericial no se acompaña para ser llevado a juicio oral como prueba, sino para servir a las funciones propias de la preparación del juicio. A partir de la Ley No 20.074 (publicada en el Diario Oficial el 14 de noviembre del 2005), que estableció la actual redacción de estas disposiciones del CPP, es evidente que esta exigencia de entregar el informe escrito es para los efectos del examen de admisibilidad que debe hacer el juez de garantía y no para ser presentado ante el tribunal oral. Así se ha uniformado la doctrina en el punto73. La admisión de la pericia como prueba documental carece de sustento en la legislación actual (Duce Julio 2016).

\section{RESULTADOS}

\section{RESULTADOS}

En el Perú el proceso de admisibilidad no está regulada en el código de Procedimientos penales, aunque si contenida en el código procesal penal del 2004 (Art. 385). Se encuentra bajo la exclusiva competencia del Juez, quien toma en cuenta los criterios de admisibilidad: relevancia, pertinencia, utilidad, necesidad. El tribunal constitucional señala que, una de las garantías que asiste las partes a las partes del proceso es la de presentar los medios probatorios necesarios que posibiliten crear convicción en el juzgador sobre la veracidad de los argumentos. la necesidad de que sean armonizados con otros derechos o bienes constitucionales; limites extrínsecos, como la propia naturales del derecho en cuestión y limites intrínsecos (Cas, $\mathrm{N}^{\circ} 281-$ 2011- Moquegua, F.J. 3.3.). También se debe considerar criterios generales de la prueba son tres; 1) que los extremos del parámetro pericial sean de carácter técnico; 2) que los extremos del dictamen guarden relación con los hechos controvertidos; 3 ) y criterios espéciales como conocimiento experto; Idoneidad del perito, confiabilidad del peritaje.

En Colombia consagran diferentes estándares de valoración en la admisibilidad de la prueba a cargo de los jueces. Aplican reglas de la experiencia, la ciencia y la lógica, cuenta para ello las normas procesales penales existentes en la ley 906 de 2004, como son los artículos 344 inciso final, 357 inciso final de dicha ley procesal, en concordancia con los principios de pertinencia y admisibilidad, establecidos en los artículos 375 y 376 del citado estatuto y, además apoyándose en la jurisprudencia nacional. El artículo 376 establece: inadmisibilidad de la prueba. se toma en cuenta el uso de principios.

En Chile, Los jueces de garantía operan en la lógica, establecido en el artículo 276 inciso cuarto del CPP. La admisibilidad de esta prueba no es registrada en las resoluciones judiciales, no desarrollan las razones por 
las que se admite la evidencia. Pero si son exigencias; la necesidad del conocimiento experto, la idoneidad del experto y la confiabilidad de la información experta. El CPC en su Art, 413.2.

\section{DISCUSIÓN}

El modelo procesal penal La admisibilidad de la prueba pericial en Perú, Colombia y Chile tienen sus bases en los modelos anglosajón, pero el manejo en el proceso de admisibilidad de la prueba pericial en muy diferentes, también existe diferencia significativa en el manejo de admisibilidad en los países referenciados.

La base fundamental del modelo anglosajón es la cientificidad de la prueba pericial y se manejan criterios de valoración, estas no son aplicables en ninguno de los países referenciados cada una de ellas con sus propias características en Chile y Colombia el proceso de admisibilidad se encuentra sostenidos su sustento jurídico en el Perú Los criterios de manejo de admisibilidad de la prueba pericial en el Perú no está regulada en el código de Procedimientos penales, aunque si contenida en el código procesal penal del 2004 (Art. 385). Lo valioso es que se establece los limites extrínsecos, como la propia naturales del derecho en cuestión y limites intrínsecos (Cas, $\mathrm{N}^{\circ} 281$ - 2011- Moquegua, F.J. 3.3.), así mismo Chile en el juez admitirá la prueba pericial cuando considere que los peritos otorgan suficientes garantías de seriedad u profesionalismo.

\section{CONCLUSIONES}

Es necesario elevar las exigencias de admisibilidad de la prueba pericial en Sudamérica con un incursionamiento progresivo de valoración en cuanto a la cientificidad de la prueba pericial.

Los modelos procesales penales en el Perú, Colombia y Chile son semejantes de origen anglosajón, pero los manejos de admisibilidad de la prueba pericial son muy diferentes.

EL Perú no con cuenta con legislación exclusiva para los procesos de admisibilidad de la prueba pericial, es urgente un cambio a nivel legislativo y jurisprudencial.

\section{AGRADECIMIENTOS}

A la escuela de posgrado de la Universidad Nacional del Altiplano, a nuestro docente de Producción intelectual del Doctorado de Derecho Dr. Boris Espezua Salmón, por sus enseñanzas y la oportunidad de publicar este artículo de revisión.

\section{REFERENCIAS BIBLIOGRÁFICAS}

Aguilar, Cristian. 2014. "La Prueba En El Proceso Penal Oral.” 31(2003).

Azarcón, Reynaldo Bustamante. 1997. “El Derecho Fundamental a Probar y Su Contenido Esencial." IUS ET VERITAS: Revista de la Asociación IUS ET VERITAS 8(14): 171-85.

Bordalí, Andrés, and Hunter Iván. 2013. “JUICIOS ORALES EN CHILE.” : 157-90.

Bustamante, Monica. 2010. “La Relación Del Estándar de Prueba de La Duda Razonable y La Presunción de Inocencia Desde El Garantismo Procesal and Presumption of Innocence from Procedural Warranty in Colombian Criminal Trial." Opinion Juridica 9(17): 71-91.

Córdova Pardo, Vanessa Elizabeth. 2019. “Análisis de La Actividad Probatoria de Oficio En El Proceso Penal: A Propósito Del Principio de Imparcialidad Judicial.” : 1-68. https://pirhua.udep.edu.pe/bitstream/handle/110 42/4319/DER_161.pdf?sequence=1\&isAllowed $=y$.

Duce Julio, Mauricio. 2016. "Los Informes En Derecho Nacional y Su Admisibilidad Como Prueba a Juicio En El Proceso Penal Chileno." Revista de derecho (Valdivia) 29(1): 297-327.

Estrada Vélez, Sergio. 2016. "Los Principios Generales Del Derecho En El Artículo 230 de La Constitución Política ¿Normas Morales o Normas Jurídicas?” Opinión Jurídica 15(30): 47-66. 
Ferrer, Jordi. 2008. “La Valoración Racional de La Prueba.” 28: 277-337.

Iriarte, Gustavo Cuello. 2005. "Pontificia Universidad Javeriana." : 491-510.

Jiménez Ramírez, Milton César. 2014. "Procedencia de La Acción de Tutela Contra Sentencias." Academia \& Derecho 5(8): 37-69.

Lizcano, Pedro lain, and Isabel Barbosa. 2011. "El Juicio de Admisibilidad de Las Solicitudes Probatorias Por Vía Excepcional, Dentro Del Ciclo de La Audiencia Del Juicio Oral, En El Sistema Penal Acusatoeio Colombiano." UNIVERSIDAD DE MEDELLÍN EN CONVENIO CON LA U. LIBRE DE PEREIRA.

Lluch, Abel. 2013. “La Valoracion de La Prueba En El Proceso Civil." 61: 13-38.

Ore, Arsenio. 2018. “Manual de Derecho Procesal Penal, La Prueba En El Proceso Penal.” Journal of Linguistics 3(2): 139-57. https://www.euskalit.net/archivos/201803/modelogestionavanzada_2018.pdf?1\%0Ahttps://dialnet .unirioja.es/servlet/articulo?codigo=4786739\%0Ahttps://www2.deloitte.com/content/dam/Deloitte/mx/D ocuments/human-capital/HCT-2018.pdf\%0Ahttp://pepsic.bvsalud.org/pd.

Ortiz, Marin Elizabeth Jaqueline. 2018. ““ Universidad Nacional De Cajamarca „.” Universidad Nacional de Cajamarca: 1-55. http://repositorio.unc.edu.pe/handle/UNC/1009\%0Ahttp://repositorio.unc.edu.pe/bitstr eam/handle/UNC/2987/Tesis completa Ronald Romero.pdf?sequence=1\&isAllowed=y.

Osco Escobedo, Miguel. 2019. "La Admisibilidad y El Valor Probatorio de La Evidencia Digital En El Sistema Jurídico Peruano 2018.” Universidad César Vallejo.

Ramos, Bernardo. 2013. "Regulación, Admisibilidad y Valoración de La Prueba Pericial Penal En El Derecho Nacional."

Reyna, Luis. "Proceso Penal Aplicado."

Varga, Rikell. 2018. 1 La Valoracion De La Pueba Pericial En El Prceso Penal. 